\title{
Effect of Oral Calcium Administration on Metabolic Status and Uterine Health of Dairy Cows With Reduced Postpartum Rumination and Eating Time
}

Pablo Pinedo ( $\sim$ pinedop@colostate.edu )

Colorado State University https://orcid.org/0000-0001-7111-3377

\section{Diego Manríquez}

Colorado State University

Nicolas Marota

Aurora Organic Farms

Giuliano Mongiello

Aurora Organic Farms

\section{Carlos Risco}

Oklahoma State University

Leen Leenaerts

Aurora Organic Farms

Hans Bothe

Aurora Organic Farms

Juan Velez

Aurora Organic Farms

\section{Research article}

Keywords: Rumination, Eating, Metabolic, Metritis

Posted Date: January 27th, 2021

DOI: https://doi.org/10.21203/rs.3.rs-153484/v1

License: (c) (1) This work is licensed under a Creative Commons Attribution 4.0 International License. Read Full License 


\section{Abstract}

\section{Background}

Hypocalcemia has detrimental effects on health and performance of dairy cows. As hypocalcemic cows show reduced feed intake, we hypothesized that cows with lower rumination and eating time (CRET) may benefit from Ca supplementation. The objective was to evaluate the effect of postpartum oral $\mathrm{Ca}$ administration on metabolic status ( $\mathrm{Ca}$, fatty acids [FA], and $\beta$-Hydroxybutyrate [BHB] serum concentrations) and incidence of puerperal metritis (PM) in dairy cows with reduced postpartum CRET. Cows diagnosed with reduced CRET ( $<489 \mathrm{~min} / \mathrm{d} ; \mathrm{n}=88$ ) during the first day postpartum were assigned into 1 of 2 treatments: i) Calcium administration $(\mathrm{CA} ;=45)$ that received $1 \mathrm{Ca}$ oral capsule (Bovikalc bolus, Boehringer Ingelheim, St. Joseph, MO) containing $\mathrm{CaCl} 2$ and $\mathrm{CaSO} 4$ (43 g of $\mathrm{Ca}$ ) once per day, for 3 consecutive days, starting at $\mathrm{d} 1$ postpartum; and ii) Control $(\mathrm{CON} ; \mathrm{n}=43)$ that did not receive oral $\mathrm{Ca}$. A convenience group consisting of cows with CRET $\geq 489 \mathrm{~min} / \mathrm{d}$ was used for comparison and did not receive oral $\mathrm{Ca}(\mathrm{NOR} ; \mathrm{n}=96)$.

Results

At day 1 postpartum cows with lower CRET had lower Ca serum concentrations (CA=2.08 $\mathrm{mmol} / \mathrm{L}$; $\mathrm{CON}=2.06 \mathrm{mmol} / \mathrm{L})$ compared with NOR cows $(2.17 \mathrm{mmol} / \mathrm{L})$. Calcium concentrations at $\mathrm{d} 3,5$, and 12 postpartum were not different among the three groups. Serum FA concentrations at $d 1,3$ and 5 postpartum were higher in both CA and CON cows compared with NOR. At d 12, only CA cows had higher FA concentrations than NOR cows. Serum BHB concentrations at $d 3$ were highest in CA, with no difference between CON and NOR. At d 5, BHB concentrations were higher in CA, followed by CON, and NOR. No effect was observed for $\mathrm{Ca}$ administration on incidence of PM and reproductive performance. CON cows had lower survival at 30 DIM (86.5\%) than NOR cows $(97.9 \%)$.

\section{Conclusions}

Cows with reduced CRET during the first day postpartum had lower $\mathrm{Ca}$ concentration and altered metabolic status following parturition. Oral calcium administration did not affect incidence of metabolic disorders nor reproductive health and subsequent pregnancy. Compared with normal cows, survival at 30 days in milk was lower for non-Ca supplemented cows with CRET.

\section{Background}

Metabolic changes occurring at the time of calving represent a significant challenge for dairy cows [1]. The abrupt increase in nutrient requirements to support milk synthesis at a time when feed intake is depressed results in a shift from a positive to a negative energy balance that leads to fat mobilization and elevated fatty acids (FA) concentrations. Coincidently, peripartal synthesis and secretion of colostrum causes major losses of $\mathrm{Ca}$ in blood $[2,3,4]$ and subclinical or clinical hypocalcemia may occur [5]. 
Hypocalcemic cows have decreased feed intake and rumination, increased plasma concentrations of cortisol and FA [6, 7, 8], limited numbers of neutrophils with phagocytic activity $[4,8,9]$, and reduced concentrations of cytosolic $\mathrm{Ca}^{2+}$ in mononuclear cells [3]. The altered metabolic status and the impaired innate immune function of hypocalcemic cows leads to increased incidence of metritis and other diseases $[4,10]$, higher risk of culling, and reduced milk production and reproductive performance [11].

Oral Ca supplementation has been proposed as a complement to dietary strategies to manage hypocalcemia in dairy herds [12]. Although the effect of oral Ca supplementation has been reported to be beneficial on the reduction of clinical hypocalcemia [13], the impact of this practice in cows receiving an acidogenic diet before calving has not been extensively evaluated [14]. Furthermore, a recent study [15] reported that responses to oral Ca supplementation were conditional on parity and production potential of cows. Oral Ca supplementation was detrimental to reproduction in primiparous cows. On the contrary, Ca supplementation benefited reproduction in multiparous cows and milk yield in the cohort of multiparous cows of higher production potential. Consequently, it is plausible to suggest that, to optimize the effect of Ca supplementation, cows at the highest risk of hypocalcemia should be targeted.

A significant limitation for the implementation of strategies for oral Ca supplementation is that the identification of subclinically hypocalcemic cows remains impractical, as clinical signs of this condition are not evident. However, cows with reduced concentrations of Ca show behavioral changes, such as reduced rumination and eating activity $[8,10,16,17]$, that could be identified by remote sensor technology. Furthermore, because hypocalcemic cows are more likely to develop metritis and other diseases, we anticipated that cows at higher risk of developing puerperal metritis (PM) could be identified early after calving by use of remote sensor technology to assess rumination and eating activity. Consequently, we hypothesized that early postpartum supplementation with oral $\mathrm{Ca}$ to cows with reduced feed intake and rumen activity identified by remote sensors would mitigate the effect of lower blood Ca concentrations and metabolic status, reducing the occurrence of metritis improving subsequent fertility. Therefore, the objective was to evaluate the effect of postpartum oral $\mathrm{Ca}$ administration on metabolic status (total $\mathrm{Ca}$, fatty acids [FA], and $\beta$-Hydroxybutyrate [BHB] serum concentrations) and incidence of PM in dairy cows with reduced rumination and eating time. Other outcomes of interest included reproductive performance and survival up to 30 DIM.

\section{Results}

\section{Descriptive statistics}

The pre-enrollment analyses to determine a cut-off value for reduced postpartum rumination and eating time (CRET) demonstrated a significant association between CRET at $d 1$ postpartum and the occurrence of PM within the first 12 DIM. Healthy cows had CRET $193.2(\mathrm{~min} / \mathrm{d})$ longer than PM cows on the day of calving ( $490.7 \pm 8.7$ vs. $297.5 \pm 53 \mathrm{~min} / \mathrm{d} ; P=0.0003)$. The area under the curve for the ROC analysis was 0.86 , when a cut-off value of $489 \mathrm{~min} / \mathrm{d}$ of CRET was considered in the model. The resulting sensitivity 
and specificity were 0.55 and 0.90 , respectively. Therefore, cows in this study were classified according to their CRET during the first day postpartum as normal or having reduced CRET (CRET $<489 \mathrm{~min} / \mathrm{d}$ ).

Based on this categorization,184 lactating Holstein cows (57 primiparous and 127 multiparous) were enrolled in the study (calcium administration $[\mathrm{CA}]=45$; control $[\mathrm{CON}]=43$; unaffected controls $[\mathrm{NOR}]=$ 96) at $d 1$ postpartum (Figure 1). One CON cow was euthanized due to toxic mastitis at 2 days postpartum, while 6 cows $(C A=1 ; C O N=3 ; N O R=2)$ were sold within 12 days postpartum. Therefore, 178 and 177 cows were evaluated at $d 5$ and $d 12$, respectively.

Average \pm SD parity were $2.98 \pm 1.68,3.16 \pm 1.67$, and $2.35 \pm 1.66$ for CA, CON, and NOR, respectively $(P=$ 0.08 ). Median (range) for lactation number in the overall population and in multiparous cows were 2 ( 1 8) and $3(2-8)$, respectively. The proportions of primiparous cows were $\mathrm{CA}=33 \%$; $\mathrm{CON}=26 \%$, and NOR $=$ $32 \%(P=0.67)$. Average CRET at d 1 postpartum were $395.1 \pm 80.9 \mathrm{~min} / \mathrm{d}, 401.5 \pm 80.0 \mathrm{~min} / \mathrm{d}$, and 619.1 $\pm 80.0 \mathrm{~min} / \mathrm{d}$ for CA, CON, and NOR, respectively $(P<0.001)$. Average CRET by group from $\mathrm{d} 1 \mathrm{to} \mathrm{d} 7$ postpartum are presented in Figure 2. For multiparous cows, NOR had higher CRET values than CA and CON cows in all time points $(P<0.01)$. On the contrary, in primiparous cows there was no consistent trend to determine differences among the three treatments over time.

\section{Postpartum metabolic status}

All blood metabolites changed over time $(P<0.05)$, independent of $\mathrm{Ca}$ administration. Average $\pm \mathrm{SEM}$ serum total $\mathrm{Ca}$ concentrations within $24 \mathrm{~h}$ postpartum were lower in $\mathrm{CA}(P<0.001)$ and $\operatorname{CON}(P<0.001)$, compared with NOR cows $(C A=2.08 \pm 0.03 \mathrm{mmol} / \mathrm{L}$ vs. $\mathrm{CON}=2.06 \pm 0.03 \mathrm{mmol} / \mathrm{L}$ vs. $\mathrm{NOR}=2.17 \pm 0.02$ $\mathrm{mmol} / \mathrm{L}$ ). The $\mathrm{Ca}$ concentrations in CA and CON cows were below the threshold considered to define sub clinical hypocalcemia ( $\mathrm{SCH}$ ) [4]. No significance for the interaction between treatment and parity was established $(P=0.41)$ and no differences in serum Ca concentrations were determined among groups from $\mathrm{d} 3$ to $\mathrm{d} 12$ (Figure 3 ).

Average serum FA concentrations within $24 \mathrm{~h}$ postpartum were higher in $\mathrm{CA}(P=0.002)$ and $\operatorname{CON}(P=$ 0.009 ), compared with NOR cows (CA $=0.71 \pm 0.04 \mathrm{mmol} / \mathrm{L} ; \mathrm{CON}=0.65 \pm 0.04 \mathrm{mmol} / \mathrm{L}$; and NOR $=0.48$ $\pm 0.03 \mathrm{mmol} / \mathrm{L})$, but no difference was established between CA and CON groups ( $P=0.97)$. An effect for the interaction between treatment and parity was determined at $24 \mathrm{~h}$ postpartum $(P=0.02)$; only multiparous cows showed significant differences among treatments $(C A=0.80 \pm 0.04 \mathrm{mmol} / \mathrm{L}$ vs. NOR $=$ $0.48 \pm 0.03 \mathrm{mmol} / \mathrm{L}[P<0.001] ; \mathrm{CON}=0.65 \pm 0.04 \mathrm{mmol} / \mathrm{L}$ vs. NOR $[P=0.02]$ ) (Figure 3). No differences among groups were determined for average serum $\mathrm{BHB}$ concentrations within $24 \mathrm{~h}$ postpartum. However, higher BHB serum concentrations were observed in CA vs. CON $(P=0.04)$ and NOR $(P<0.001)$ at $\mathrm{d} 3$ postpartum. At $d 5$ postpartum BHB serum concentrations were higher in CA vs. CON $(P=0.04)$ and NOR $(P=0.01)$ cows. Cows in CON had higher BHB values than NOR cows only at $\mathrm{d} 5(P=0.04$; Figure 3$)$. Additional comparisons for $\mathrm{Ca}, \mathrm{FA}$, and BHB between reduced CRET and NOR cows (CON and CA combined) as are presented in Figure 3. 
Results for the association of treatment and CRET status with SCH, severe lipomobilization (SLM), and subclinical ketosis (SCK), while controlling for parity, can be found in Table 1. There was no effect of treatment or CRET status on the odds of $\operatorname{SCH}(P=0.09$ and $P=0.08$, respectively), however there was an effect observed for both on the odds of SLM $(P=0.001$ and $P<0.001$, respectively $)$ and SCK $(P=0.01$ and $P=0.008$, respectively). A tendency for lower $\mathrm{SCH}$ was determined in primiparous cows $(P=0.08)$ and the odds of SLM were more than double in primiparous than in multiparous cows $(P=0.03)$.

\section{Effect of treatment on puerperal metritis}

The association of treatment and CRET status with prevalence of PM at d 5 and d 12, while controlling for parity, are shown in Table 2. The only significant differences were determined at d 12 for CA vs. NOR groups $(P=0.02)$ and for reduced CRET vs. NOR $(P=0.04)$. Although prevalence of PM at $\mathrm{d} 5$ was higher in primiparous than in multiparous cows (8.8\% vs. $14.3 \%)$, the effect of parity on PM at $d 5$ or at $d 12$ was not significant $(P=0.23$ and $P=0.32$, respectively). When both examination times where considered, cure rates at $\mathrm{d} 12$ were $22.2 \%, 33.3 \%$, and $55.6 \%$ for $\mathrm{CA}, \mathrm{CON}$, and NOR, respectively, with no difference by group.

\section{Effect of treatment on pregnancy and survival}

No significant differences by group were found for the proportions of cows pregnant at 200 days postpartum (LSM for CA = 39.8\%; CON = 38.3\%; and NOR = 47.3\%; $P=0.2$ ). Survival at 30 days postpartum were $93.3 \%, 86.1 \%$, and $97.9 \%$ for CA, CON and NOR cows, respectively $(P=0.02)$. No significant differences in survival at 30 days postpartum were found for CA vs. CON and for CA vs. NOR, but the odds of survival for cows in CON were $0.16(0.03-0.85 ; P=0.03)$ times the odds of survival of NOR cows.

\section{Discussion}

Due to the critical impact of reduced feed intake around calving on mineral and metabolic status, we anticipated that cows at higher risk of developing hypocalcemia and subsequent PM could be identified early after calving by use of sensor technology. Consequently, early postpartum supplementation with oral Ca to cows with reduced CRET would mitigate the effect of lower blood Ca concentrations, reducing the occurrence of puerperal metritis and improving subsequent fertility.

Supporting this concept, our preliminary analyses in the study farm indicated an association between reduced CRET at d 1 postpartum and the subsequent occurrence of PM, as healthy cows spent $193 \mathrm{~min} / \mathrm{d}$ longer than PM cows eating and ruminating during the day of calving. Although in this study this association was not replicated at d 5 postpartum, the odds of PM at d 12 were greater in cows with reduced CRET than in NOR cows.

The potential association between altered peripartal eating and rumination behavior and metabolic and reproductive disorders has been explored $[4,18,19]$ and the adoption of health alerts provided by remote 
sensor technology is growing among farmers [20]. In a study by Liboreiro et al. [21], cows diagnosed with metritis had reduced rumination times during postpartum, while Stangaferro et al. [18] reported that the combination of activity and rumination was effective in identifying cows with severe cases of metritis or cows with metritis and another health disorder. In a study by Schirmann et al. [22], cows with metritis and SCK had lower dry matter intake during the precalving period and continued to eat less until $\mathrm{d} 20$ postpartum, as compared with healthy cows. In agreement, Sahar et al. [23] reported that cows that spend less time eating during the first 90 min after fresh feed delivery in the prepartum period were at increased risk of developing SCK and metritis in the postpartum period. Interestingly, to the authors' knowledge, the use of daily CRET to test these associations has not been widely explored. As both eating and rumination behaviors are affected before metritis presentation, it is plausible to suggest that this combination may be advantageous.

The concept of strategic $\mathrm{Ca}$ administration in specific subpopulations of cows has been proposed. Oetzel and Miller [14] determined that lame cows and higher producing cows responded favorably to oral $\mathrm{Ca}$ administration. In a more recent study, Martinez et al. [15] reported that responses to oral $\mathrm{Ca}$ supplementation depended on parity and milk production. Notably, while oral Ca supplementation benefited reproduction and increased milk yield in high producing multiparous cows, Ca supplementation had a negative effect in fertility of primiparous animals. Despite this indication of undesirable effects of Ca administration in primiparous cows, a proportion of first parity cows was included in the current study to test the consistency of the detrimental effect of reduced CRET across lactations. In addition, the interaction between treatment and parity was of interest. Notably, in this study this interaction was not significant and primiparous cows responded similarly to multiparous animals to treatment. The main finding associated with parity category was that, contrary to multiparous, in primiparous cows there was no consistent trend in CRET values to determine differences among the three treatments over time (Figure 2).

As anticipated, in the current study the two groups with reduced CRET at $d 1$ postpartum had lower serum Ca concentrations $(\mathrm{SCH})$, while serum FA concentrations were higher compared with NOR cows. In agreement with this finding, a recent study by Goff et al. [17] indicated that normocalcemic cows spent more time ruminating on the first day after calving than subclinically hypocalcemic cows or cows with milk fever. Moreover, plasma Ca concentration at $12 \mathrm{~h}$ postpartum was also correlated with rumination rate on the second day after calving, even though blood Ca concentrations had increased in most cows by $\mathrm{d} 2$.

The link between postpartum rumination and metabolic disorders was explored by Soriani et al. [24] that indicated a negative correlation between rumination time and BHB. Similarly, Stangaferro et al. [25] described higher plasma concentrations of FA and BHB and lower concentrations of $\mathrm{Ca}$ in cows with altered values of an index combining rumination time and physical activity. Moreover, a recent study by Pérez-Báez et al. [26] demonstrated that cows that developed ketosis had reduced postpartum DMI relative to their $\mathrm{BW}$. 
Interestingly, in the present study samples between $\mathrm{d} 3$ and $\mathrm{d} 12$ postpartum indicated no differences in concentrations of $\mathrm{Ca}$ between the supplemented and the untreated reduced CRET group and between these two groups and NOR cows (Figure 3). A transient increase in serum Ca concentration was observed at $d 3$ only in CA cows, but the magnitude of the difference relative to CON cows was not large enough to indicate significance and serum $\mathrm{Ca}$ concentrations returned to lower values at $\mathrm{d} 5$. In agreement with this modest short-lasting effect, Oetzel and Miller [14] reported that administration of oral Ca did not improve ionized Ca concentrations 20 hours after bolus administration, while Melendez et al. [27] concluded that oral Ca supplements resulted in no effect on plasma concentrations of $\mathrm{Ca}$.

Considering the potential inability of sustaining adequate concentrations of serum $\mathrm{Ca}$ after administration, the dose of Ca used in the current study ( $43 \mathrm{~g} / \mathrm{d}$ of Ca for $3 \mathrm{~d}$ ) was higher than that of two previous reports $[14,28]$, where 1 or 2 oral Ca boluses containing $43 \mathrm{~g}$ of Ca were administered after calving. Although it is plausible to infer that the dose of Ca supplementation used in these studies was insufficient, higher concentrations of Ca supplementation $(86 \mathrm{~g} / \mathrm{d}$ of $\mathrm{Ca}$ on $\mathrm{d} 0$ and 1 postpartum, followed by $43 \mathrm{~g} / \mathrm{d}$ on d 2, 3, and 4 postpartum) tested by Martinez et al. [15, 29] reduced SCH but increased the incidence of metritis and negatively affected reproduction in primiparous cows considered to be at reduced risk of metritis. In our study, a clear assessment of the impact of treatment on serum Ca concentrations following calving and the duration of this effect in CA cows was not possible due to the lack of post treatment samples on $\mathrm{d} 1$ and $\mathrm{d} 2$, which is a limitation of the current study.

Although cows at higher risk of hypocalcemia and suboptimal metabolic and health status were identified by use of CRET, the calcium treatment intervention was not effective on the outcomes evaluated. Relevant to our main objective, no difference was established in SCH incidence between CA and CON cows, indicating that the proposed $\mathrm{Ca}$ administration was not successful on reducing this condition (Table 1). However, when CA and CON cows were compared with NOR, only CON cows had higher incidence of $\mathrm{SCH}$ and a tendency for higher $\mathrm{SCH}$ was determined for cows with reduced CRET.

As reported by Grummer et al. [1], limited feed intake evidenced by reduced CRET had a consistent effect on the incidences of overall SLM and SCK when all the sampling points were combined. Incidences of overall SLM were higher in CA and CON compared with NOR, as was also the case for SCK in CA vs. NOR. Overall, incidences of SCH, SLM, and SCK were higher than those reported in other studies [30]. This could reflect the specific dynamics of the study farm, as well as the criteria used in this study, where at least one positive result within the four consecutive samples was enough to consider a cow affected. The use of this criteria results in increments in sensitivity, but an increase in the proportion of false positives is also expected. Nonetheless, this discrepancies with values in other populations suggest caution regarding the external validity of these findings.

The lack of effect of Ca supplementation on serum concentrations of $\mathrm{Ca}$, FA, or BHB in the current study agrees with data reported by Melendez et al. [27], that also administered oral Ca to multiparous cows with no effect. Moreover, FA and BHB were higher in the Ca supplemented group than in CON at $\mathrm{d} 3$ and at $\mathrm{d} 3$ and d 5 , respectively (Figure 3). Interestingly, primiparous cows had higher incidence of SLM, which 
disagrees with data presented by McArt et al. [31, 32]. Additionally, only multiparous cows evidenced treatment group differences for SLM incidence within $24 \mathrm{~h}$ postcalving. An explanation for this finding would be conjectural due to the information available in this study.

In the current study cows with reduced CRET during the first day postpartum had lower serum Ca concentrations and altered metabolic status. However, in disagreement with previous reports ([18, 21], no differences in the occurrence of PM at $d 5$ among treatments or between reduced CRET and NOR were found. At $d$ 12, though, the odds of PM were more than four times higher for CA than for NOR and, when CA and CON groups were combined, the odds of PM were more than three times higher for reduced CRET cows than for NOR cows. Therefore, the suggested association between reduced CRET and PM was only partially replicated in this study.

When cure rates at $\mathrm{d} 12$ were compared, no significant differences were found for any of the group comparisons. This lack of response to $\mathrm{Ca}$ administration agrees with the study by Pinedo et al. [33], were supplementing oral calcium at the time of PM treatment had no effect on clinical cure, defined as the combination of absence of fever and (vaginal discharge score) VDS $<4$ at $\mathrm{d} 6$ and 12 post treatment.

The association between $\mathrm{SCH}$ and reproductive disorders has been extensively reported $[34,35,36]$ and may be in part related to the lack of adequate ionized Ca concentrations required for uterine smooth muscle contractions [7], together with limited supply of glucose and ionized Ca for competent immune function. Interestingly, cows diagnosed with PM at d 5 had lower concentrations of serum Ca compared with healthy cows $(2.06 \mathrm{mmol} / \mathrm{L}$ vs. $2.18 \mathrm{mmol} / \mathrm{L})$, which agrees with the study by Pinedo et al. [33] where cows affected with PM had lower calcium concentrations at diagnosis $(1.57 \mathrm{mmol} / \mathrm{L}$ ) compared with matched control healthy cows $(2.10 \mathrm{mmol} / \mathrm{L})$ and the prevalence of serum $\mathrm{Ca}<2.15 \mathrm{mmol} / \mathrm{L}$ was 90 and $49 \%$ for PM and healthy groups, respectively.

Although not significant, the lower prevalence of PM at $\mathrm{d} 5$ in primiparous compared to multiparous cows was an unexpected finding that contradicts previous reports indicating a higher risk for metritis in primiparous cows associated with a higher need for calving assistance [37]. A possible explanation for this contradictory finding may be the study exclusion criterium for cows with severe dystocia, which is the main reason for higher levels of metritis in primiparous cows.

The required sample size for this study was calculated anticipating a beneficial effect of treatment on metabolic status. Specifically, a difference in FA serum concentrations at $d 5$ postpartum in CA vs. CON that was considered. However, a limitation of the current study is that for binary outcomes, such as presentation of PM and other health disorders, considerable differences among treatments would be needed to determine statistical significance. As an example, although PM prevalence at d 5 was $20.5 \%$ vs. $9.6 \%$ in CA and NOR, due to power limitations, the magnitude of this difference was not large enough to establish statistical significance. On the contrary, at d 12 a significant difference on PM prevalence was established between CA (15.9\%) and NOR (4.2\%) groups (Table 2). 
Serum Ca concentrations in CA and CON were lower than those of NOR at d 1; however, Ca concentrations in these two groups increased and became similar to NOR by d 3 in CA and $d 5$ in CON cows. In a recent report by Neves et al. [38] plasma Ca concentration assessed at 1 postpartum was not associated with the risk of metritis in primiparous cows. However, an association was determined at 2, 3, and 4 days postpartum. An increased risk of metritis was established at 2 DIM for 2nd lactation animals and at 4 DIM for 3rd and higher lactation. In a second study by that group [39], immediate postpartum plasma Ca concentrations (within $12 \mathrm{~h}$ of parturition) were poor predictors of metritis. In the study presented here, CRET cows had average Ca serum concentrations lower than NOR cows only at $1 \mathrm{DIM}$. In agreement with the findings presented by Neves et al. [38, 39], the transient nature of lower Ca concentrations in CA and CON could be an explanation for the lack of a clear association between treatment and PM in this study.

Subclinical hypocalcemia is a well-described risk factor for reduced reproductive performance and increased risk of culling. Cows with $\mathrm{SCH}$ had reduced estrous cyclicity, pregnancy at first Al, and extended median days to pregnancy $[4,11]$. The exclusive use of natural service in the study farm provided a unique opportunity for testing fertility differences in the treatments without the potential effect of variable estrus detection efficiency and compliance in estrus synchronization protocols. In addition, all cows were exposed to bulls for natural service at the same day postpartum and therefore had similar days postpartum for breeding. Possible factors explaining the low percentage of cows pregnant at $200 \mathrm{DIM}$ could be that breeding took place in summer, as the study cows calved at the end of spring (April to July). In addition, due to prohibitions in the use of hormones in organic certified systems, none of the cows were subjected to any type of estrus or ovulation synchronization protocol.

Our results show that $\mathrm{Ca}$ administration had no effect in pregnancy at $200 \mathrm{DIM}$, although there was a difference in the LSM of 7.5 and 9 percent points for NOR vs. CA and CON cows, respectively. The lack of differences in pregnancy between $\mathrm{CON}$ and $\mathrm{Ca}$ supplemented cows is in partial agreement with previous research on PM cows supplemented with $\mathrm{Ca}$ after diagnosis [40]. Although in that study $\mathrm{Ca}$ supplementation to PM cows increased the proportion of cows inseminated by 150 DIM, no effect on pregnancy was determined. Interestingly, in a study by Martinez at al. [29], Ca supplementation to primiparous cows resulted in reduced P/Al at first and all artificial inseminations, extended median days to pregnancy, and smaller proportion of pregnant cows. However, Ca supplementation to multiparous cows improved P/Al at the first and all artificial inseminations, resulted shorter days to pregnancy and increased proportion of pregnant cows.

In the current study there was lower survival at 30 DIM in CON cows compared with NOR cows (86.5\% vs. $97.9 \%)$. Although survival was higher in calcium supplemented cows (93.3\%) than in CON cows, this difference was not significant. Interestingly, PM cows did not have lower survival than healthy cows, which contrasts with a previous report where survival at 30 DIM were $72.6 \%$ and $84.1 \%$ for two groups of cows with PM, compared with $98 \%$ in healthy matched controls [33].

\section{Conclusions}


Cows identified through sensor data with reduced rumination and eating activity during the first day postpartum had lower serum concentrations of calcium and altered metabolic status following parturition. Oral calcium administration to cows with reduced rumination had a transient increase on total calcium serum concentrations but did not affect incidence of SCH, SLM, or SCK nor reproductive health and subsequent pregnancy. Compared with normal cows, survival at 30 days postpartum was lower for non-Ca supplemented cows with reduced rumination and eating time.

\section{Methods}

\section{Study Population}

The study population consisted of Holstein cows calving from April 23 to July 14, 2019 in a single certified organic dairy farm (1,230 milking cows) located in Northern Colorado, USA. All cows were housed in dry lots, with access to shade and shelter that included straw bedding. Prepartum primiparous and multiparous cows were comingled. Cows were milked twice daily, and milk yield was recorded and analyzed for fat, protein, and SCS monthly for individual cows. The rolling herd average milk production was $8,100 \mathrm{~kg}$. Cows were fed a TMR twice a day to meet or exceed the nutritional requirements for a lactating Holstein cow producing $30 \mathrm{~kg} / \mathrm{d}$ of milk with $3.5 \%$ fat and $3.1 \%$ true protein [41]. During the grazing season (April to September), cows had access to pasture and grazing provided at least $30 \%$ of the DMI of the total ration. The TMR was based on corn silage (5 to 7\%), wheat silage (17 to 19\%), grain mix containing soy bean, soy hulls, corn, wheat, and minerals and vitamins (38 to $41 \%$ ), sorghum silage ( 5 to $7 \%$ ), alfalfa hay ( $2 \%$ ), grass hay ( 0 to $1.5 \%$ ), and pasture grazing (estimates as 30 to $38 \%$ ).

Grazing management consisted of rotational grazing in pastures based on perennial forages, alfalfa, Italian rye grass, oat rye grass, and teff grass. Through the study period prepartum diet was based on corn silage (10.5 to $16.0 \%$, DM basis), wheat silage (10.5 to $16.6 \%$ ), alfalfa hay (32 to $41 \%$ ), grass hay (14.2 to $20 \%$ ), grain mix (12.6 to $19.2 \%$ ), and mineral and vitamin mix (3.8\%). Anionic salts were included into the ration (dietary cation anion difference $=-100 \mathrm{mEq} / \mathrm{kg}$ ).

Cows enrolled in the study were subjected to a reproductive program based on natural service. Cows were moved to the bull pens at $30 \mathrm{DIM}$ and pregnancy diagnosis was performed by transrectal palpation of the uterus and its content on a weekly basis. Cows diagnosed non pregnant were checked every two weeks. Due to prohibitions in the use of hormones in organic certified systems, none of the cows were subjected to any type of estrus or ovulation synchronization protocol.

\section{Case Definitions and Treatment Allocation}

All cows that calved during the study period, starting on April 23, 2019, were eligible for enrollment. Cows that had calving related problems (severe dystocia, cesarean section, fetotomy, stillbirth, twins, or uterine prolapse) were excluded from enrollment. Individual CRET ( $\mathrm{min} / \mathrm{d})$ was determined using previously validated accelerometers (CowManager SensOor, Agis Automatisering BV, Harmelen, the Netherlands) tagged in the left ear $[42,43]$. The accelerometers were designed to differentiate spatial movements of 
the ear being associated to rumination, eating, and activity (walking-running) and provided a reliable approximation of the time cows spent ruminating and eating. As this was a regular management practice in the study farm, all the cows were affixed with the accelerometer as heifers.

To identify an adequate cut-off maximizing CRET sensitivity and specificity to determine the risk for PM, a retrospective analysis was completed considering 480 cows housed in the study dairy. The analysis was performed using cow records prior to the start of the study. These data consisted of a single cohort of cows (primiparous $=152$; multiparous $=328$ ) with lactations started between October 2018 and March 2019 (mean \pm SD lactation number $=2.6 \pm 1.6$ ). The association between CRET at $d 1$ postpartum and the occurrence of PM within the first 12 DIM was tested by ROC analysis, maximizing the area under the curve and the combined values for sensitivity and specificity. The CRET value selected for cut-off in this population was $489 \mathrm{~min} / \mathrm{d}$.

Consequently, for the current study, cows were classified according to their CRET during the first day postpartum as normal or having reduced CRET (CRET $<489 \mathrm{~min} / \mathrm{d}$ ). Cows diagnosed with reduced CRET were blocked by parity $(1 ; \geq 2)$ for treatment allocation. The assignment of the first cow in each block (primiparous/multiparous) was determined by tossing a coin, followed by a sequential allocation into 1 of 2 treatments: ( 1$)$ Calcium administration $(C A ; n=45)$ received 1 Ca oral capsule (Bovikalc bolus, Boehringer Ingelheim, St. Joseph, MO) once per day, for 3 consecutive days; and (2) Control (CON; n = 43) did not receive calcium administration. A convenience group consisting of cows with CRET $\geq 489 \mathrm{~min} / \mathrm{d}$ was enrolled as unaffected controls that remained untreated (NOR; $n=96)$.

Calcium oral capsules contained $\mathrm{CaCl} 2$ and $\mathrm{CaSO} 4$ ( $43 \mathrm{~g}$ of $\mathrm{Ca}$ ). The total dose for the 3 days treatment regimen was $129 \mathrm{~g}$ of $\mathrm{Ca}(43 \mathrm{~g} / \mathrm{d})$ per cow. The total amount of $\mathrm{Ca}$ administered for the complete treatment was larger than that reported by Oetzel and Miller [14] and Sampson et al. [28] that supplemented cows with 1 or 2 oral Ca boluses (Bovikalc bolus, Boehringer Ingelheim, St. Joseph, MO) after calving. None of the study cows in the three groups received any oral or parenteral Ca other than the treatments described above and the Ca contained in the diet.

\section{Postpartum Health-Monitoring Program, Outcomes of Interest, and Independent Variables}

All postpartum cows were monitored daily for general health from calving to $12 \mathrm{DIM}$. Monitoring was performed between 0600 and $0800 \mathrm{~h}$, following the AM milking. Main parameters considered were appetite, appearance (depressed, dehydrated), and characteristics of vaginal discharge (color, consistency, and odor). Cows that appeared abnormal on any of these parameters were submitted for clinical examination by a veterinarian.

Enrolled cows fitting our inclusion criteria had complete clinical examination performed by a veterinarian blinded to allocation groups and the nature of treatments at enrollment and at $\mathrm{d} 5$ and 12 postpartum. Vaginal discharge was evaluated using the Metricheck device (Metricheck, SimcroTech, Hamilton, New

Zealand) and scored (VDS) according to Chenault et al. [44] as follows: $0=$ no discharge observed; $1=$ not fetid, normal lochia (viscous; red, brown, or clear); 2 = not fetid; thick mucus; cloudy, clearing, or clear; 
3 = not fetid; may be purulent, mucopurulent, or chocolate brown; or 4 = fetid; may be red or pink to chocolate brown; thin, serous, and watery; with or without pieces of necrotic tissue. Rectal temperature (RT) was measured using an electronic thermometer (GLA Agricultural Electronics, San Luis Obispo, CA). Cows with PM were defined as having an abnormally enlarged uterus with VDS of 4, signs of systemic illness (dullness, or other signs of toxemia) and fever $\left(\mathrm{RT} \geq 39.5^{\circ} \mathrm{C}\right)$ [45]. Cows with PM were treated according to the study farm health protocols. Treatments were applied every other day for a total of 3 consecutive treatments as follows: Cows received $3.75 \mathrm{~mL}$ of Optimum UterFlush (Van Beek Natural Science, USA, containing yucca extract, cinnameldahyde, thymol, and a proprietary blend of carvacrol [4isopropyl-2-methylphenol]) diluted in $117 \mathrm{~mL}$ of distilled water intrauterus. In addition, all PM treated cows received hypertonic saline solution ( $500 \mathrm{~mL}$ of $7.2 \%$ i.v.), dextrose $(500 \mathrm{~mL}$ of $50 \%$ i.v.), and oral aspirin [5 boluses ( $15.6 \mathrm{~g}$ of acetylsalicylic acid/bolus)/ $\mathrm{d}$ for $3 \mathrm{~d}$ ]. According to organic certification, no antibiotic therapies were used in the study farm. Clinical cure in cows treated for PM at $d 5$ was defined as the combination of absence of fever and VDS $<4$ at $d 12$ examination [44].

All the enrolled cows had whole-blood samples collected from the middle coccygeal vein using 20-gauge needles into sterile glass Vacutainer tubes without anticoagulant (BD Vacutainer Precision Glide, Becton Dickinson, Franklin Lakes, $\mathrm{NJ}$ ). All samples were collected following the AM milking, between 0600 and $0800 \mathrm{~h}$, before oral $\mathrm{Ca}$ administration. Samples were refrigerated and centrifuged at $1,500 \times g$ for $15 \mathrm{~min}$ at $18^{\circ} \mathrm{C}$ within $2 \mathrm{~h}$ of collection. Serum was harvested and stored frozen at $-80^{\circ} \mathrm{C}$ for subsequent analyses at the Veterinary Diagnostic Laboratories at Colorado State University (Fort Collins, CO). Sampling points included $24 \mathrm{~h}$ after calving and $\mathrm{d} 3,5$, and 12 postpartum and the analyses included total $\mathrm{Ca}, \mathrm{FA}$, and BHB determination, as this is the period when cows typically experience reduced blood Ca concentrations $[3,28]$ and negative energy balance [46] (Figure 1).

Subclinical hypocalcemia was considered when serum Ca concentration $\leq 2.14 \mathrm{mmol} / \mathrm{L}$ [4]. Lactating cows were under severe lipomobilization (SLM) if serum FA concentration $\geq 0.6 \mathrm{mmol} / \mathrm{L}[46,47]$.

Subclinical ketosis (SCK) was defined as serum BHB $\geq 1.0 \mathrm{mmol} / \mathrm{L}$ for sampling points at $\mathrm{d} 1,3$, and 5 and serum $B H B \geq 1.4 \mathrm{mmol} / \mathrm{L}$ for $\mathrm{d} 12[11,46,48,49]$. Overall $\mathrm{SCH}$, severe negative energy balance, or SCK status were determined for each study cow considering all the blood sample collection points ( $1=$ at least one positive result at $d 1,3,5,12$ postpartum).

Pregnancy diagnosis outcomes and dates of removal from the herd and the recorded reason for exit were also exported from PCDART ${ }^{\circledR}$ (Dairy Records Management Systems, Raleigh, NC), for assessment of reproductive performance (percentage of cows pregnant at $200 \mathrm{DIM}$ ) and survival at $30 \mathrm{DIM}$.

\section{Statistical Analysis}

The experimental design was a randomized block design with cows with reduced CRET blocked by parity $(1 ; \geq 2)$ and assigned randomly into 1 of 2 treatments. Sample size calculations were performed using the data analysis application SAS Power and Sample Size (release 9.4; SAS, Inst. Inc., Cary, NC). The sample size was calculated anticipating the potential impact of oral Ca supplementation in reduced CRET cows 
on metabolic status. Considering the reported association between elevated serum concentrations of FA and health and fertility outcomes [47,50], this metabolite was used in the calculations. Previously reported FA values were considered in the calculations $[5,8,15]$. The goal was to detect a difference of $0.09 \mathrm{mmol} / \mathrm{L}$ in FA serum concentrations at $\mathrm{d} 5$ postpartum in CA $(0.71 \mathrm{mmol} / \mathrm{L})$ vs. CON $(0.80 \mathrm{mmol} / \mathrm{L})$ cows. Considering SD $=0.17 \mathrm{~mm} / \mathrm{L}$ and power $=80 \%$ and confidence $=95 \%$, the number of cows required to determine a significant difference between the 2 groups was estimated in 44 cows per group.

The cut-off for reduced CRET was determined before enrollment from a preliminary dataset within the study farm, including individual general data, rumination and eating times, as well as PM events. The association between CRET at $\mathrm{d} 1$ postpartum and the occurrence of PM within the first 12 DIM was tested by ROC analysis. Receiving operating characteristic curves were created using the ROC option in PROC LOGISTIC. This option generated classification tables with probability levels containing sensitivity and specificity values. Multiple cut-off values were tested maximizing the area under the curve and the combined values for sensitivity and specificity. The CRET value selected for cut-off in this population was $489 \mathrm{~min} / \mathrm{d}$.

Rumination and eating times were collected as $\mathrm{min} / \mathrm{h}$ from calving until $30 \mathrm{DIM}$. Individual CRET were summarized into min/d using the PROC SQL procedure. Daily LSM for CRET were estimated for PM and healthy cows using PROC MIXED for repeated measures. This model considered PM status and DIM, and an interaction term between PM status and DIM, with cow nested within treatment was included as a random effect. The association between increments of CRET at calving day and the likelihood of PM was assessed using PROC LOGISTIC including the classification table option for determining the AUC and the probability levels to calculate the cut-offs of CRET that maximized sensitivity and specificity.

All data were exported to Microsoft Excel (Microsoft Corp., Redmond, WA), where the information was organized for further analysis using SAS. The appropriate randomization of cows at the time of enrollment for discrete outcomes (parity number and proportion of primiparous cows) was analyzed by the Chi-square test (PROC FREQ). Logistic regression (PROC GLIMMIX) was used for the analysis of PM binary outcome variables (SCH, SLM, SCK) with results reported as adjusted odds ratios. Continuous variables (metabolites concentrations) were evaluated by ANOVA (PROC MIXED). For both types of variables, treatment (combined treatments) and parity category $(1 ; \geq 2)$, considered as a potential confounder, were forced in the final models. The initial models included parity category by treatment interaction as covariable. This effect was considered for inclusion at $P<0.10$. Repeated measures analyses using the MIXED procedure, assuming an exchangeable covariance structure, were used to test the effects of treatment, parity category, and blood sampling day relative to calving (time of sampling) for each blood metabolite (total $\mathrm{Ca}, \mathrm{FA}, \mathrm{BHB}$ ). Time of sampling was included as a repeated measure with cow nested within treatment considered as a random effect. The interaction effects treatment by parity category and treatment by sampling day were included in the initial models, but only the interaction treatment by sampling day remained in the final models. The Tukey multiple differences test was used to compare treatments by day where appropriate. The analyses tested differences among treatments (CA vs. CON. Vs. NOR), as well as between reduced CRET (CA + CON) and normal CRET (NOR). All results are 
expressed as adjusted odds ratios and least squares means with their respective $95 \%$ confidence intervals or standard errors. Significance and tendency levels were declared at $P<0.05$ and $P<0.1$, respectively.

\section{Abbreviations}

BHB: $\beta$-Hydroxybutyrate; CA: Calcium administration group; CON: control group; CRET: combined rumination and eating time; FA: fatty acids; LSM: Least squares means; MP: multiparous cows; NEB: negative energy balance; NOR: normal unaffected controls; PM: puerperal metritis; $\mathrm{SCH}$ : subclinical hypocalcemia; SCK: subclinical ketosis SLM: severe lipomobilization; VDS: vaginal discharge score.

\section{Declarations}

\section{Ethics approval and consent to participate}

The Institutional Animal Care and Use Committee at Colorado State University reviewed and approved all procedures that the study animals underwent for this trial (Protocol ID: 19-8877A). Consent was obtained from the owner.

\section{Consent for publication}

Not Applicable

\section{Availability of data and materials}

Data sets generated from this study are available upon request to the corresponding author.

\section{Competing interests}

The authors declare no competing interests for the submission of this article.

\section{Funding}

The authors acknowledge the USDA (USA-NIFA OREI award number 2016-51300-25734) and the USDA (NIFA AFRI Translational Genomics for Improved Fertility of Animals award number 2013-68004) for financial support to perform this study. The funders provided resources for laboratory analyses and visits to the study farm. The funders had no role in study design, data collection and analysis, decision to publish, or preparation of the manuscript.

\section{Author's contributions}

PP: experimental design, statistical analysis, manuscript preparation. DM: experimental design, data collection, statistical analysis, manuscript preparation. NM, GM, and LL: treatment administration, health 
checking, and sampling. CR: Manuscript preparation. JV, HB: experimental design, monitoring and sampling logistics. All authors have read and approved the manuscript.

\section{Acknowledgements}

The authors thank Aurora Organic Dairy for facilitating the use of animals and facilities, as well as all the assistance from the farm's personnel throughout the study.

\section{Author details}

${ }^{1}$ Department of Animal Sciences, Colorado State University, Fort Collins, CO 80523-1171, USA

${ }^{2}$ Aurora Organic Farms, Platteville, CO 80651-9009, USA

${ }^{3}$ College of Veterinary Medicine, Oklahoma State University, Stillwater, OK, 74078-2005, USA

\section{References}

[1] Grummer RR, Mashek DG, Hayirli A. Dry matter intake and energy balance in the transition period. Veterinary Clinics of North America-Food Animal Practice. 2004;20(3):447-+.

[2] Horst RL, Goff JP, Reinhardt TA. Adapting to the transition between gestation and lactation: Differences between rat, human and dairy cow. J Mammary Gland Biol Neoplasia. 2005;10(2):141-56.

[3] Kimura K, Reinhardt TA, Goff JP. Parturition and hypocalcemia blunts calcium signals in immune cells of dairy cattle. J Dairy Sci. 2006;89(7):2588-95.

[4] Martinez N, Risco CA, Lima FS, Bisinotto RS, Greco LF, Ribeiro ES, et al. Evaluation of peripartal calcium status, energetic profile, and neutrophil function in dairy cows at low or high risk of developing uterine disease. J Dairy Sci. 2012;95(12):7158-72.

[5] Reinhardt TA, Lippolis JD, McCluskey BJ, Goff JP, Horst RL. Prevalence of subclinical hypocalcemia in dairy herds. Vet J. 2011;188(1):122-4.

[6] Horst RL, Jorgensen NA. Elevated plasma-cortisol during Induced and spontaneous hypocalcemia in ruminants. J Dairy Sci. 1982;65(12):2332-7.

[7] Hansen SS, Norgaard P, Pedersen C, Jorgensen RJ, Mellau LSB, Enemark JD. The effect of subclinical hypocalcaemia induced by $\mathrm{Na}(2)$ EDTA on the feed intake and chewing activity of dairy cows. Vet Res Commun. 2003;27(3):193-205.

[8] Martinez N, Sinedino LDR, Bisinotto RS, Ribeiro ES, Gomes GC, Lima FS, et al. Effect of induced subclinical hypocalcemia on physiological responses and neutrophil function in dairy cows. J Dairy Sci. 2014;97(2):874-87. 
[9] Ducusin RJT, Uzuka Y, Satoh E, Otani M, Nishimura M, Tanabe S, et al. Effects of extracellular Ca2+ on phagocytosis and intracellular $\mathrm{Ca} 2+$ concentrations in polymorphonuclear leukocytes of postpartum dairy cows. Res Vet Sci. 2003;75(1):27-32.

[10] Seifı HA, LeBlanc SJ, Leslie KE, Duffield TF. Metabolic predictors of post-partum disease and culling risk in dairy cattle. Vet J. 2011;188(2):216-20.

[11] Chapinal N, Carson ME, LeBlanc SJ, Leslie KE, Godden S, Capel M, et al. The association of serum metabolites in the transition period with milk production and early-lactation reproductive performance. $J$ Dairy Sci. 2012;95(3):1301-9.

[12] Oetzel GR. Oral calcium supplementation in peripartum dairy cows. Veterinary Clinics of North America-Food Animal Practice. 2013;29(2):447-+.

[13] Thilsing-Hansen T, Jorgensen RJ, Ostergaard S. Milk fever control principles: a review. Acta Vet Scand. 2002;43(1):1-19.

[14] Oetzel GR, Miller BE. Effect of oral calcium bolus supplementation on early-lactation health and milk yield in commercial dairy herds. J Dairy Sci. 2012;95(12):7051-65.

[15] Martinez N, Sinedino LDP, Bisinotto RS, Daetz R, Risco CA, Galvao KN, et al. Effects of oral calcium supplementation on productive and reproductive performance in Holstein cows. J Dairy Sci. 2016;99(10):8417-30.

[16] Goff JP. The monitoring, prevention, and treatment of milk fever and subclinical hypocalcemia in dairy cows. Vet J. 2008;176(1):50-7.

[17] Goff JP, Hohman A, Timms LL. Effect of subclinical and clinical hypocalcemia and dietary cationanion difference on rumination activity in periparturient dairy cows. J Dairy Sci. 2020;103(3):2591-601.

[18] Stangaferro ML, Wijma R, Caixeta LS, Al-Abri MA, Giordano JO. Use of rumination and activity monitoring for the identification of dairy cows with health disorders: Part III. Metritis. J Dairy Sci. 2016;99(9):7422-33.

[19] Paudyal S, Maunsell FP, Richeson JT, Risco CA, Donovan DA, Pinedo PJ. Rumination time and monitoring of health disorders during early lactation. Animal. 2018;12(7):1484-92.

[20] Eckelkamp EA, Bewley JM. On-farm use of disease alerts generated by precision dairy technology. J Dairy Sci. 2020;103(2):1566-82.

[21] Liboreiro DN, Machado KS, Silva PRB, Maturana MM, Nishimura TK, Brandao AP, et al. Characterization of peripartum rumination and activity of cows diagnosed with metabolic and uterine diseases. J Dairy Sci. 2015;98(10):6812-27. 
[22] Schirmann K, Chapinal N, Weary DM, Vickers L, von Keyserlingk MAG. Short communication: Rumination and feeding behavior before and after calving in dairy cows. J. Dairy Sci. 2013;96(11):70887092.

[23] Sahar MW, Beaver A, von Keyserlingk MAG, Weary DM. Predicting Disease in Transition Dairy Cattle Based on Behaviors Measured Before Calving. Animals. 2020;10(6).

[24] Soriani N, Trevisi E, Calamari L. Relationships between rumination time, metabolic conditions, and health status in dairy cows during the transition period. J Anim Sci. 2012;90(12):4544-54.

[25] Stangaferro ML, Wijma R, Caixeta LS, Al-Abri MA, Giordano JO. Use of rumination and activity monitoring for the identification of dairy cows with health disorders: Part I. Metabolic and digestive disorders. J Dairy Sci. 2016;99(9):7395-410.

[26] Perez-Baez J, Risco CA, Chebel RC, Gomes GC, Greco LF, Tao S, et al. Association of dry matter intake and energy balance prepartum and postpartum with health disorders postpartum: Part II. Ketosis and clinical mastitis. J Dairy Sci. 2019;102(10):9151-64.

[27] Melendez P, Donovan A, Risco CA, Hall MB, Littell R, Goff J. Metabolic responses of transition Holstein cows fed anionic salts and supplemented at calving with calcium and energy. J Dairy Sci. 2002;85(5):1085-92.

[28] Sampson JD, Spain JN, Jones C, Carstensen L. Effects of Calcium Chloride and Calcium Sulfate in an Oral Bolus Given as a Supplement to Postpartum Dairy Cows. Vet Ther. 2009;10(3).

[29] Martinez N, Sinedino LDP, Bisinotto RS, Daetz R, Risco CA, Galvao KN, Thatcher WW, and Santos JEP. Effects of oral calcium supplementation on productive and reproductive performance in Holstein cows. 2016. J. Dairy Sci. 99(10):8417-30

[30] Ospina PA, Mcart JA, Overton TR, Stokol T, Nydam DV. Using Nonesterified Fatty Acids and betaHydroxybutyrate Concentrations During the Transition Period for Herd-Level Monitoring of Increased Risk of Disease and Decreased Reproductive and Milking Performance. Veterinary Clinics of North AmericaFood Animal Practice. 2013;29(2):387-412.

[31] Mcart JAA, Nydam DV, Oetzel GR. Dry period and parturient predictors of early lactation hyperketonemia in dairy cattle. J Dairy Sci. 2013;96(1):198-209.

[32] McArt JAA, Nydam DV, Oetzel GR, Overton TR, Ospina PA. Elevated non-esterified fatty acids and beta-hydroxybutyrate and their association with transition dairy cow performance. Vet $\mathrm{J}$. 2013a;198(3):560-70.

[33] Pinedo PJ, Velez JS, Bothe H, Merchan D, Pineiro JM, Risco CA. Effect of intrauterine infusion of an organic-certified product on uterine health, survival, and fertility of dairy cows with toxic puerperal metritis. J Dairy Sci. 2015;98(5):3120-32. 
[34] Curtis CR, Erb HN, Sniffen CJ, Smith RD, Powers PA, Smith MC, et al. Association of parturient hypocalcemia with eight periparturient disorders in Holstein cows. J Am Vet Med Assoc. 1983;183(5):55961.

[35] Risco CA, Reynolds JP, Hird D. Uterine Prolapse and Hypocalcemia in Dairy-Cows. J Am Vet Med Assoc. 1984;185(12):1517-9.

[36] Chapinal N, Carson M, Duffield TF, Capel M, Godden S, Overton M, et al. The association of serum metabolites with clinical disease during the transition period. J Dairy Sci. 2011;94(10):4897-903.

[37] Giuliodori MJ, Magnasco RP, Becu-Villalobos D, Lacau-Mengido IM, Risco CA, de la Sota RL. Metritis in dairy cows: Risk factors and reproductive performance. J Dairy Sci. 2013;96(6):3621-31.

[38] Neves RC, Leno BM, Bach KD, Mcart JAA. Epidemiology of subclinical hypocalcemia in early-lactation Holstein dairy cows: The temporal associations of plasma calcium concentration in the first 4 days in milk with disease and milk production. J Dairy Sci. 2018;101(10):9321-31.

[39] Neves RC, Leno BM, Curler MD, Thomas MJ, Overton TR, McArt JAA. Association of immediate postpartum plasma calcium concentration with early-lactation clinical diseases, culling, reproduction, and milk production in Holstein cows. J Dairy Sci. 2018;101(1):547-55.

[40] Pinedo P, Velez J, Solano G, Rodriguez N, Naves J, Schuenemann GM, et al. Effect of oral calcium administration on the cure and reproductive performance of Holstein cows diagnosed with puerperal metritis. J Dairy Sci. 2017;100(4):2917-27.

[41] National Research Council: Nutrient requeriments of dairy cattle. 7th rev. ed. Washington, DC: Natl. Acad. Sci; 2001.

[42] Borchers MR, Chang YM, Tsai IC, Wadsworth BA, Bewley JM. A validation of technologies monitoring dairy cow feeding, ruminating, and lying behaviors. J Dairy Sci. 2016;99(9):7458-66.

[43] Pereira GM, Heins BJ, Endres MI. Technical note: Validation of an ear-tag accelerometer sensor to determine rumination, eating, and activity behaviors of grazing dairy cattle. J Dairy Sci. 2018;101(3):2492-5.

[44] Chenault JR, McAllister JF, Chester T, Dame KJ, Kausche FM, Robb EJ. Efficacy of ceftiofur hydrochloride sterile suspension administered parenterally for the treatment of acute postpartum metritis in dairy cows. Javma-Journal of the American Veterinary Medical Association. 2004;224(10):1634-9.

[45] Sheldon IM, Lewis GS, LeBlanc S, Gilbert RO. Defining postpartum uterine disease in cattle. Theriogenology. 2006;65(8):1516-30.

[46] Ospina PA, Nydam DV, Stokol T, Overton TR. Evaluation of nonesterified fatty acids and betahydroxybutyrate in transition dairy cattle in the northeastern United States: Critical thresholds for 
prediction of clinical diseases. J Dairy Sci. 2010;93(2):546-54.

[47] Ospina PA, Nydam DV, Stokol T, Overton TR. Association between the proportion of sampled transition cows with increased nonesterified fatty acids and beta-hydroxybutyrate and disease incidence, pregnancy rate, and milk production at the herd level. J Dairy Sci. 2010;93(8):3595-601.

[48] Walsh RB, Kelton DF, Duffield TF, Leslie KE, Walton JS, LeBlanc SJ. Prevalence and risk factors for postpartum anovulatory condition in dairy cows. J Dairy Sci. 2007;90(1):315-24.

[49] Chapinal N, LeBlanc SJ, Carson ME, Leslie KE, Godden S, Capel M, et al. Herd-level association of serum metabolites in the transition period with disease, milk production, and early lactation reproductive performance. J Dairy Sci. 2012;95(10):5676-82.

[50] Ospina PA, Nydam DV, Stokol T, Overton TR. Associations of elevated nonesterified fatty acids and beta-hydroxybutyrate concentrations with early lactation reproductive performance and milk production in transition dairy cattle in the northeastern United States. J Dairy Sci. 2010;93(4):1596-603.

\section{Tables}

Table 1: Results from the multivariable logistic regression analyses for occurrence of metabolic diseases by treatment during the first $12 \mathrm{~d}$ after calving. Initial models included treatment (combined treatments), parity category (forced in the final models) and the interaction treatment by parity. As no significant effect for the interaction treatment by parity was established, this term was removed from the models. 


\begin{tabular}{|c|c|c|c|c|c|c|c|c|}
\hline Condition & $\mathrm{AOR}^{1}$ & \multicolumn{3}{|c|}{$95 \% \mathrm{Cl}^{2}$} & $P$-value & \multicolumn{2}{|c|}{ Incidence } & \\
\hline \multicolumn{9}{|c|}{ Hypocalcemia (Calcium $\leq 2.14 \mathrm{mmol} / \mathrm{L}$ ) } \\
\hline & & & & & & Treatment & $+/ \mathrm{n}^{4}$ & $\%$ \\
\hline Treatment $^{3}$ & & & & & 0.09 & & & \\
\hline CA vs. CON & 0.44 & 0.15 & - & 1.31 & 0.14 & $\mathrm{CA}$ & $32 / 45$ & 71.1 \\
\hline CA vs. NOR & 1.28 & 0.59 & - & 2.79 & 0.53 & $\mathrm{CON}$ & $37 / 43$ & 86.1 \\
\hline CON vs. NOR & 2.89 & 1.10 & - & 7.65 & 0.03 & NOR & $63 / 96$ & 65.6 \\
\hline \multicolumn{9}{|l|}{ Combined treatments } \\
\hline Reduced CRET vs. NOR ${ }^{5}$ & 1.79 & 0.91 & - & 3.5 & 0.08 & & & \\
\hline \multicolumn{9}{|l|}{$\operatorname{SLM}(F A \geq 0.6 \mathrm{mmol} / \mathrm{L})^{6}$} \\
\hline Treatment & & & & & 0.001 & & & \\
\hline CA vs. CON & 0.98 & 0.35 & - & 2.79 & 0.97 & $\mathrm{CA}$ & $36 / 45$ & 80.0 \\
\hline CA vs. NOR & 3.95 & 1.71 & - & 9.15 & 0.001 & $\mathrm{CON}$ & $34 / 43$ & 79.1 \\
\hline CON vs. NOR & 4.02 & 1.71 & - & 9.43 & 0.001 & NOR & $49 / 96$ & 51.0 \\
\hline \multicolumn{9}{|l|}{ Combined treatments } \\
\hline Reduced CRET vs. NOR & 3.98 & 2.05 & - & 7.76 & $<0.001$ & & & \\
\hline \multicolumn{9}{|c|}{$\operatorname{SCK}(B H B \geq 1.0 \mathrm{mmol} / \mathrm{L}[\mathrm{d} 1-4] \text { and } \mathrm{BHB} \geq 1.4 \mathrm{mmol} / \mathrm{L}[\mathrm{d} 12])^{7}$} \\
\hline Treatment & & & & & 0.01 & & & \\
\hline CA vs. CON & 2.64 & 0.86 & - & 8.13 & 0.09 & CA & $39 / 45$ & 86.6 \\
\hline CA vs. NOR & 4.19 & 1.60 & - & 11.0 & 0.003 & $\mathrm{CON}$ & $32 / 43$ & 74.4 \\
\hline CON vs. NOR & 1.59 & 0.70 & - & 3.60 & 0.26 & NOR & $59 / 96$ & 61.4 \\
\hline \multicolumn{9}{|l|}{ Combined treatments } \\
\hline Reduced CRET vs. NOR & 2.49 & 1.27 & - & 4.91 & 0.008 & & & \\
\hline
\end{tabular}

${ }^{1}$ Adjusted odds ratio.

${ }^{2} 95 \%$ confidence interval. 
${ }^{3} \mathrm{At} \mathrm{d} 1$ postpartum, cows were classified according to their combined eating and ruminating time (CRET) as normal or having reduced time (CRET $<489 \mathrm{~min} / \mathrm{d} ; \mathrm{n}=88$ ). Cows diagnosed with reduced CRET were assigned randomly into 1 of 2 treatments: (1) Calcium supplemented (CA) received 1 Ca oral capsule (Bovikalc bolus, Boehringer Ingelheim, St. Joseph, MO) once per day, for 3 consecutive days; and (2) Control (CON) that did not receive any supplementation. A third group consisting of cows with normal levels of CRET ( $\geq 489 \mathrm{~min} / \mathrm{d}$ ) were enrolled as unaffected controls that remained untreated (NOR).

${ }^{4}$ Number of cases divided by treatment total

${ }^{5}$ Reduced CRET $=$ Combined CA and CON

${ }^{6} \mathrm{SLM}=$ Severe lipomobilization

${ }^{7}$ SKC $=$ Subclinical ketosis

Table 2: Results from the multivariable logistic regression analyses for puerperal metritis diagnosis at $\mathrm{d} 5$ and at $\mathrm{d} 12$ after calving. Models included treatment (combined treatment), parity category (forced in the final models) and the interaction treatment by parity. As no significant effect for the interaction treatment by parity was established, this term was removed from the models. 


\begin{tabular}{|c|c|c|c|c|c|c|c|c|}
\hline Condition & $\mathrm{AOR}^{1}$ & \multicolumn{3}{|c|}{$95 \% \mathrm{Cl}^{2}$} & $P$-valu & & \multicolumn{2}{|c|}{ Prevalence } \\
\hline \multicolumn{9}{|l|}{ Puerperal metritis at d 5} \\
\hline Treatment $^{3}$ & & & & & & Treatment & $+/ n^{4}$ & $\%$ \\
\hline CA vs. CON & 1.59 & 0.50 & - & 5.01 & 0.43 & $\mathrm{CA}$ & $9 / 44$ & 20.5 \\
\hline CA vs. NOR & 2.42 & 0.88 & - & 6.64 & 0.08 & CON & $6 / 40$ & 15.0 \\
\hline CON vs. NOR & 1.52 & 0.50 & - & 4.66 & 0.46 & NOR & $9 / 94$ & 9.6 \\
\hline \multicolumn{9}{|l|}{ Combined treatments } \\
\hline Reduced CRET vs. NOR ${ }^{5}$ & 1.97 & 0.81 & - & 4.80 & 0.13 & & & \\
\hline \multicolumn{9}{|l|}{ Puerperal metritis at $d 12$} \\
\hline \multicolumn{9}{|l|}{ Treatment } \\
\hline CA vs. CON & 1.74 & 0.46 & - & 6.57 & 0.41 & CA & $7 / 44$ & 15.9 \\
\hline CA vs. NOR & 4.3 & 1.18 & - & 15.6 & 0.02 & CON & $4 / 39$ & 10.3 \\
\hline CON vs. NOR & 1.47 & 0.58 & - & 10.5 & 0.22 & NOR & $4 / 94$ & 4.2 \\
\hline \multicolumn{9}{|l|}{ Combined treatments } \\
\hline Reduced CRET vs. NOR & 3.44 & 1.04 & - & 11.2 & 0.04 & & & \\
\hline
\end{tabular}

${ }^{1}$ Adjusted odds ratio.

${ }^{2} 95 \%$ confidence interval.

${ }^{3} \mathrm{At} \mathrm{d} 1$ postpartum, cows were classified according to their combined eating and ruminating time (CRET) as normal or having reduced time (CRET $<489 \mathrm{~min} / \mathrm{d} ; \mathrm{n}=88$ ). Cows diagnosed with reduced CRET were assigned randomly into 1 of 2 treatments: (1) Calcium supplemented (CA) received $1 \mathrm{Ca}$ oral capsule (Bovikalc bolus, Boehringer Ingelheim, St. Joseph, MO) once per day, for 3 consecutive days; and (2) Control (CON) that did not receive any supplementation. A third group consisting of cows with normal levels of CRET ( $\geq 489 \mathrm{~min} / \mathrm{d}$ ) were enrolled as unaffected controls that remained untreated (NOR).

${ }^{4}$ Number of cases divided by treatment total

${ }^{5}$ Reduced CRET $=$ Combined CA and CON

\section{Figures}




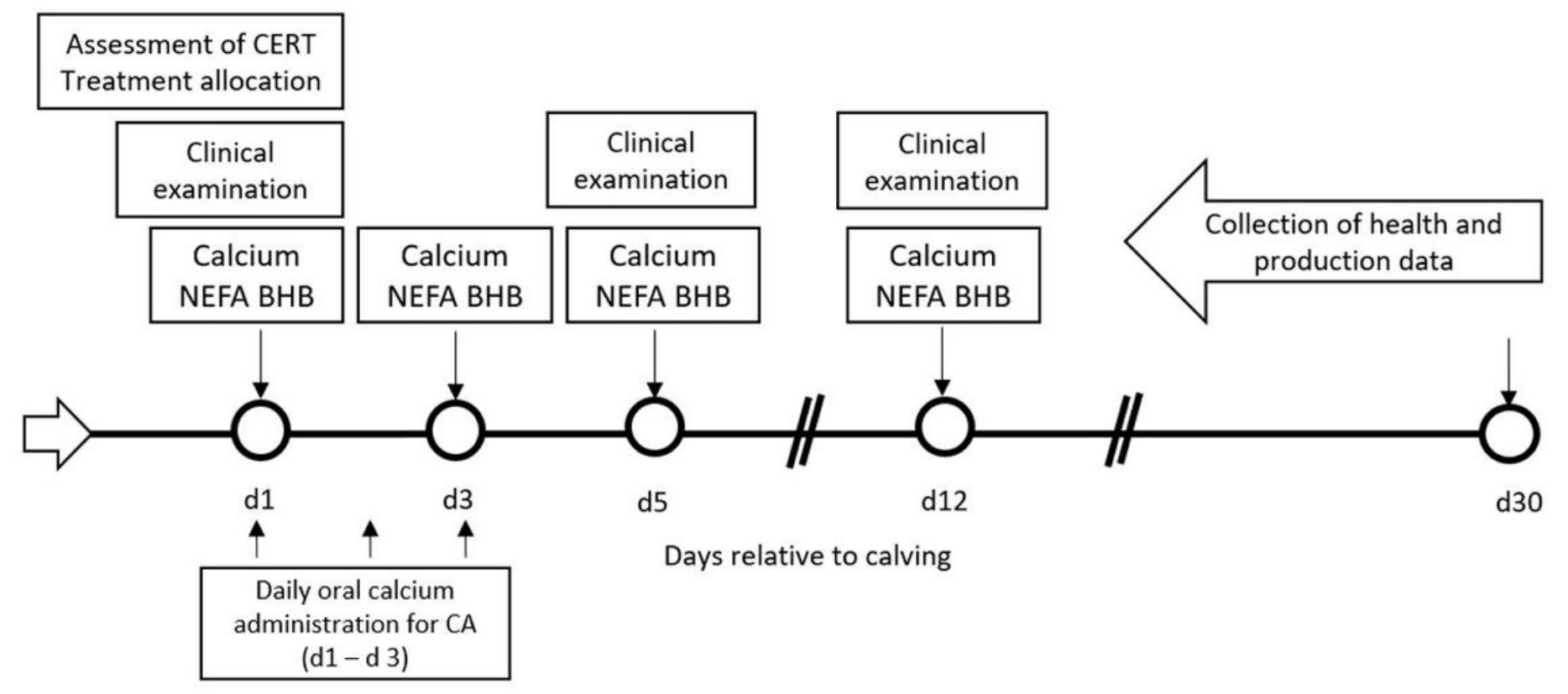

Figure 1

Study timeline in days relative to calving. At d1, postpartum cows were classified according to their combined rumination and eating time (CRET) as normal or having reduced time (CRET <489 $\mathrm{min} / \mathrm{d}$; $\mathrm{n}=$ 88). Cows diagnosed with reduced CRET were assigned randomly into 1 of 2 treatments: (1) Calcium supplemented (CA) received 1 Ca oral capsule (Bovikalc bolus, Boehringer Ingelheim, St. Joseph, MO) once per day, for 3 consecutive days; and (2) Control (CON) that did not receive any supplementation. A third group consisting of cows with normal levels of CRET ( $\geq 489 \mathrm{~min} / \mathrm{d}$ ) were enrolled as unaffected controls that remained untreated (NOR). 
Combined rumination and eating time (overall; $\mathrm{n}=184$ )
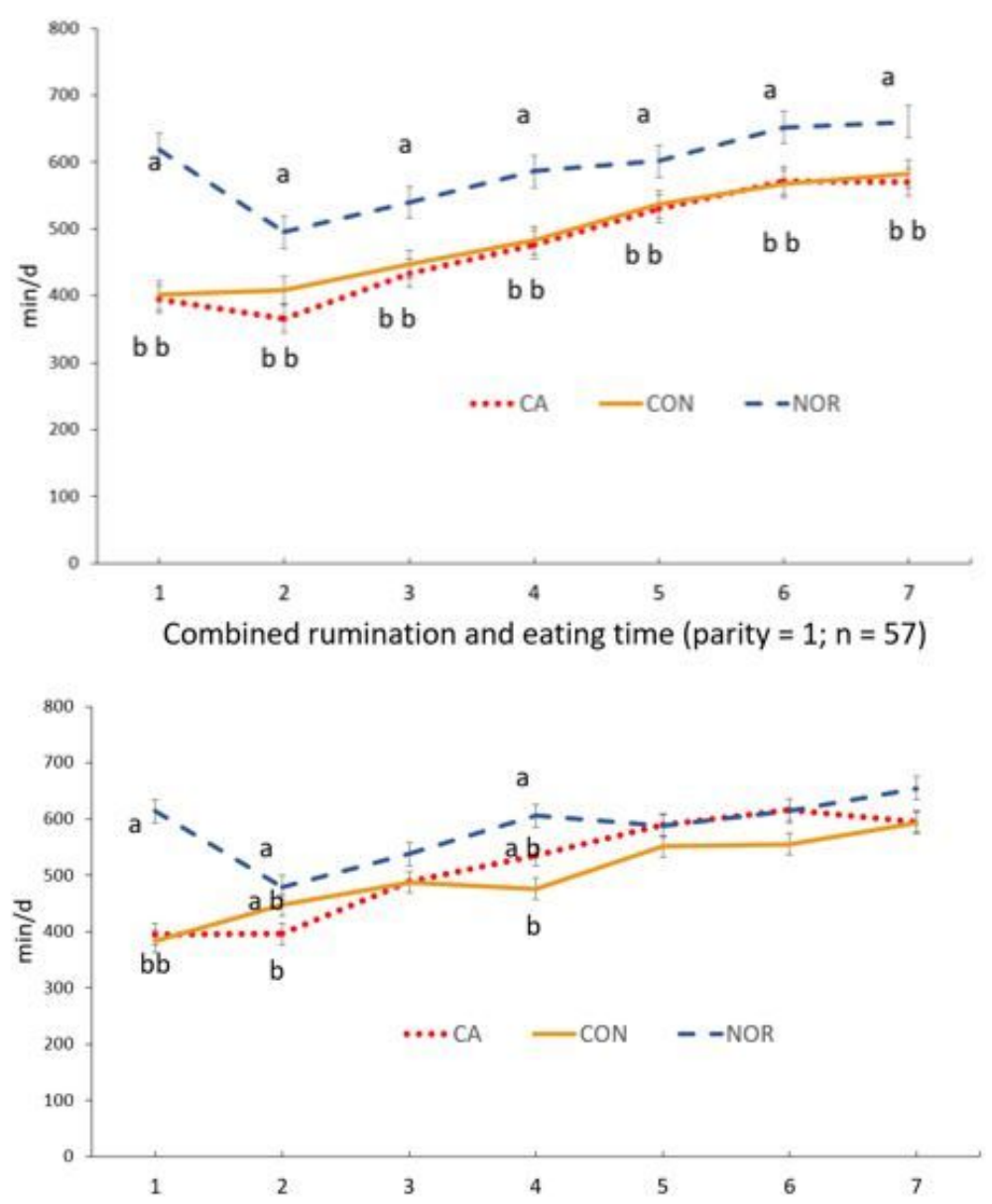

Combined eating and ruminating time (parity $\geq 2 ; n=127$ )

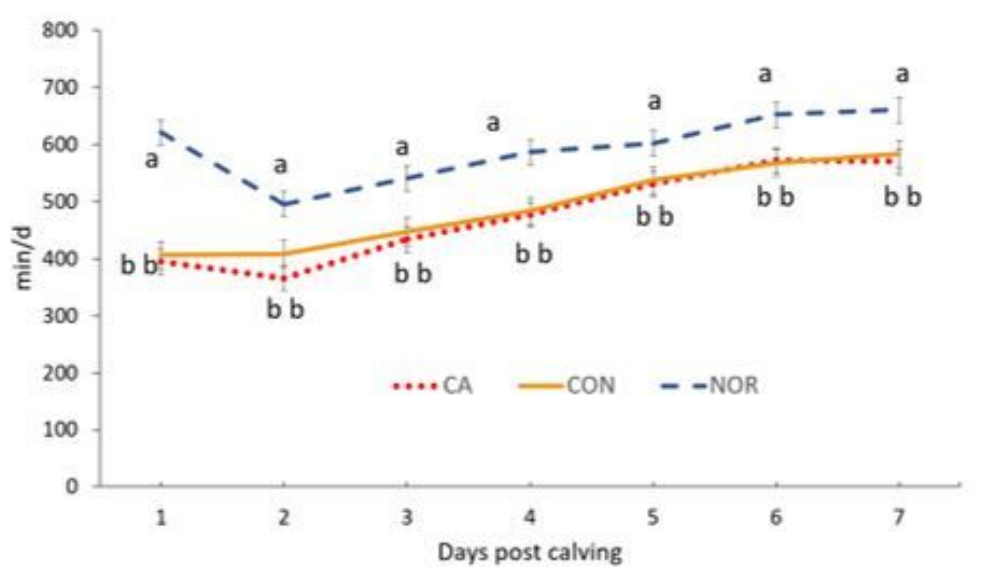

\section{Figure 2}

Least square means $( \pm$ SEM) combined rumination and eating time from $\mathrm{d} 1$ to $\mathrm{d} 7$ after calving in the overall study population (top panel), in primiparous cows (middle panel) and in multiparous cows (bottom panel). Treatments: CA (red dotted line) = reduced combined rumination and eating time (CRET), received $1 \mathrm{Ca}$ oral capsule (Bovikalc bolus, Boehringer Ingelheim, St. Joseph, MO) once per day, for 3 consecutive days; CON (orange solid line) = reduced CRET, did not receive any supplementation; NOR 
(blue dashed line) $=$ normal CRET that did not receive any supplementation. Overall population, effects of treatment $(P<0.0001)$, d post calving $(P<0.0001)$, and treatment and d post calving interaction $(P=0.8)$. Primiparous, effects of treatment $(P=0.02)$, d post calving $(P<0.0001)$, and treatment and d post calving interaction $(P=0.7)$. Multiparous, effects of treatment $(P=0.0002)$ and $d$ post calving $(P<0.0001)$, and treatment and d post calving interaction $(P=0.9)$. Different letters indicate significant differences $(P$ $<0.01$ ) between groups at specific sampling points.

Calcium $(n=184)$

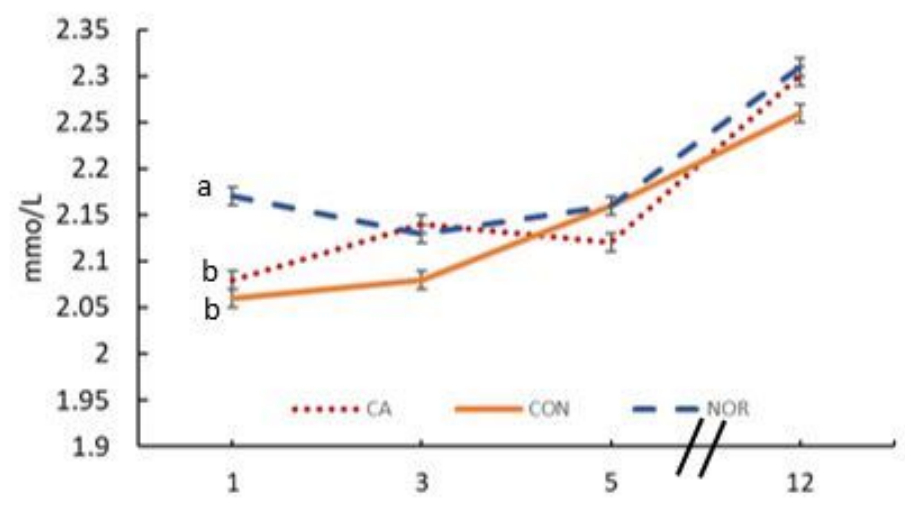

Fatty acids $(n=184)$

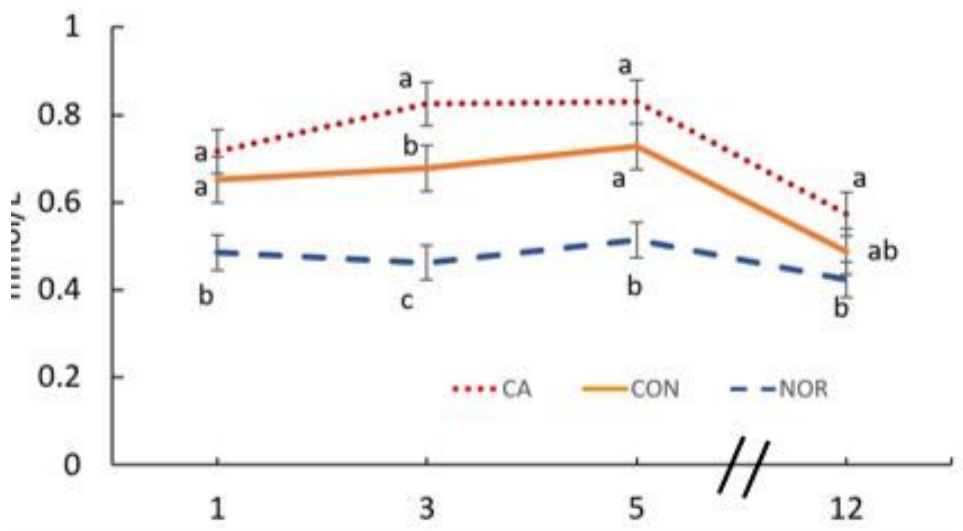

$\mathrm{BHB}(n=184)$

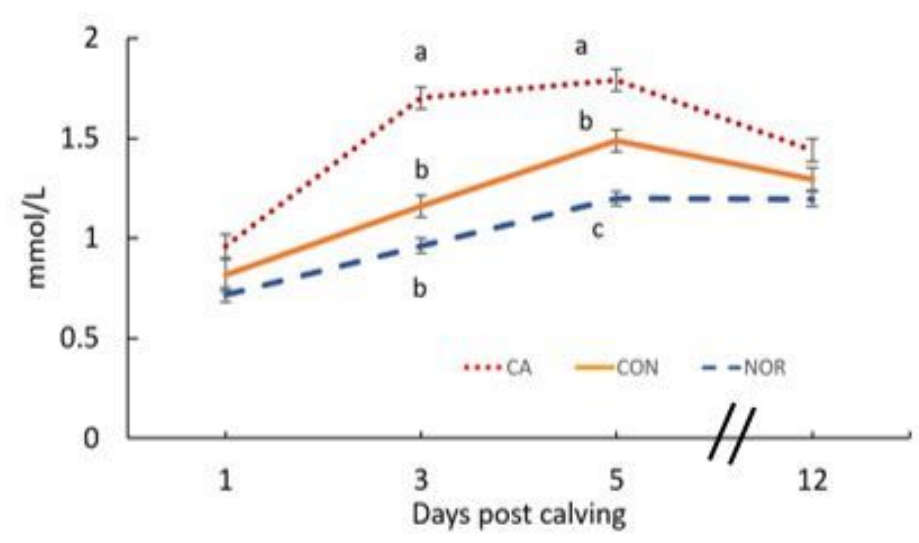

Calcium $(n=184)$

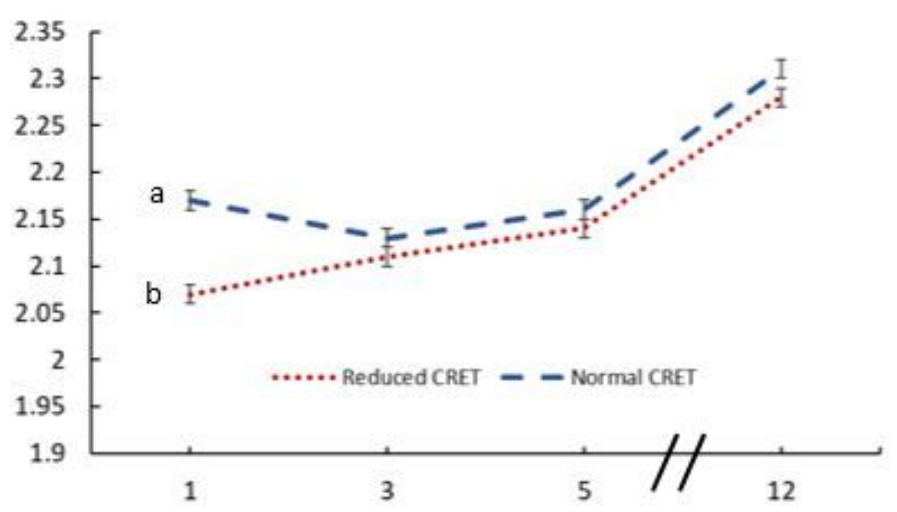

Fatty acids $(n=184)$

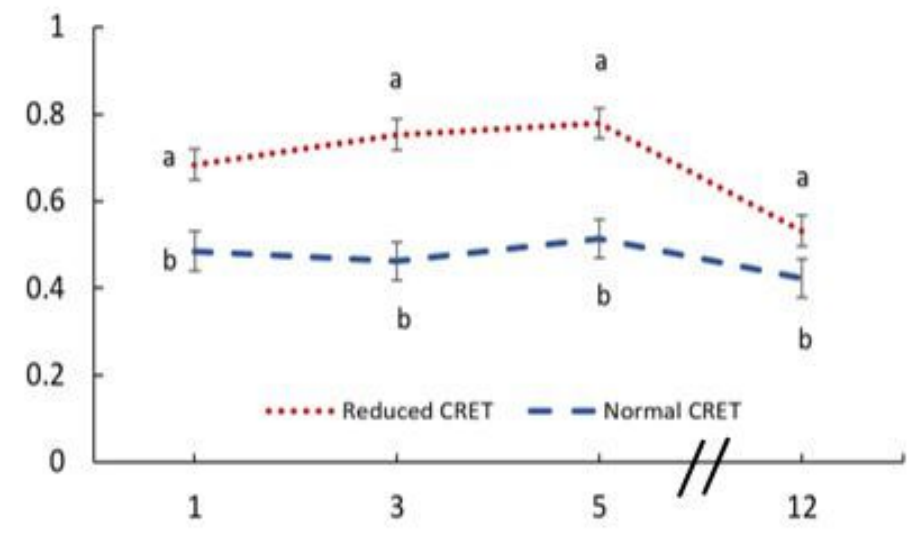

BHB $(n=184)$

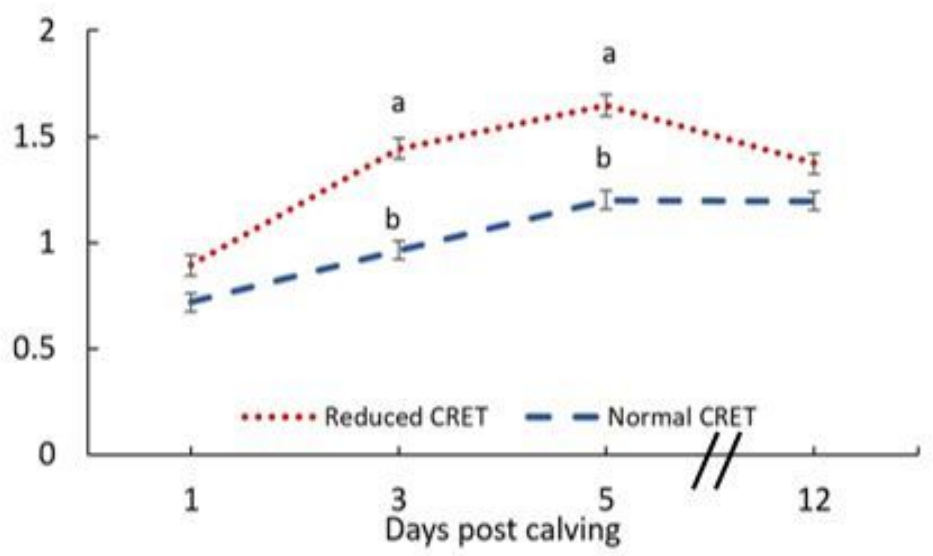

Figure 3 
Least squares means ( \pm SEM) from repeated measures analyses for postpartum $\mathrm{Ca}$, $\mathrm{FA}$, and $\mathrm{BHB}$ serum concentrations. Left panel: CA (red dotted line) = reduced combined rumination and eating time (CRET), received $1 \mathrm{Ca}$ oral capsule (Bovikalc bolus, Boehringer Ingelheim, St. Joseph, MO) once per day, for 3 consecutive days; $\mathrm{CON}$ (orange solid line) $=$ reduced $\mathrm{CRET}$, did not receive any supplementation; NOR (blue dashed line $)=$ normal CRET that did not receive any supplementation. Right panel: Normal CRET = NOR; Low CRET = CA and CON groups combined. Left panel: Calcium, effects of treatment $(P=0.03)$, parity $(P=0.002)$, d post calving $(P<0.001)$, and treatment and d post calving interaction $(P=0.017)$. Right panel: Calcium, effects of treatment $(P=0.02)$, parity $(P=0.014)$, d post calving $(P<0.001)$, and treatment and d post calving interaction $(P=0.106)$. Left panel: $F A$, effects of treatment $(P<0.0001)$, parity $(P=0.11)$, d post calving $(P<0.001)$, and treatment and $d$ post calving interaction $(P=0.03)$. Right panel: $F A$, effects of treatment $(P<0.001)$, parity $(P=0.16)$, d post calving $(P<0.001)$, and treatment and $d$ post calving interaction $(P=0.005)$. Left panel: BHB, effects of treatment $(P<0.001)$, parity $(P=0.0005)$, $d$ post calving $(P<0.001)$, treatment and d post calving interaction $(P=0.007)$. Right panel: BHB, effects of treatment $(P<0.001)$, parity $(P=0.0014)$, d post calving $(P<0.001)$, treatment and d post calving interaction $(P=0.015)$. Different letters indicate significant differences $(P<0.05)$ between groups at specific sampling points. Different letters indicate significant differences $(P<0.05)$ between groups at specific sampling points. Diagonal lines indicate a break in the $x$-axis.

\section{Supplementary Files}

This is a list of supplementary files associated with this preprint. Click to download.

- AuthorChecklistPinedo.pdf 